OPEN ACCESS

Edited by:

Prasun Kumar,

Chungbuk National University,

South Korea

Reviewed by:

Shashi Kant Bhatia,

Konkuk University, South Korea

Manabendra Mandal,

Tezpur University, India

${ }^{*}$ Correspondence:

Mamtesh Singh

s.mamtesh@yahoo.com;

mamtesh@gargi.du.ac.in

Specialty section:

This article was submitted to

Bioprocess Engineering,

a section of the journal

Frontiers in Bioengineering and

Biotechnology

Received: 01 November 2020

Accepted: 29 January 2021

Published: 19 February 2021

Citation:

Afreen $R$, Tyagi S, Singh GP and

Singh M (2021) Challenges

and Perspectives of

Polyhydroxyalkanoate Production

From Microalgae/Cyanobacteria and Bacteria as Microbial Factories:

An Assessment of Hybrid

Biological System.

Front. Bioeng. Biotechnol. 9:624885.

doi: 10.3389/fbioe.2021.624885

\section{Challenges and Perspectives of Polyhydroxyalkanoate Production From Microalgae/Cyanobacteria and Bacteria as Microbial Factories: An Assessment of Hybrid Biological System}

\author{
Rukhsar Afreen ${ }^{1}$, Shivani Tyagi', Gajendra Pratap Singh ${ }^{2}$ and Mamtesh Singh ${ }^{1 *}$ \\ ${ }^{1}$ Department of Zoology, Gargi College, University of Delhi, New Delhi, India, ${ }^{2}$ Mathematical Sciences and Interdisciplinary \\ Research Lab (Math Sci Int R-Lab), School of Computational and Integrative Sciences, Jawaharlal Nehru University, \\ New Delhi, India
}

Polyhydroxyalkanoates (PHAs) are the biopolymer of choice if we look for a substitute of petroleum-based non-biodegradable plastics. Microbial production of PHAs as carbon reserves has been studied for decades and PHAs are gaining attention for a wide range of applications in various fields. Still, their uneconomical production is the major concern largely attributed to high cost of organic substrates for PHA producing heterotrophic bacteria. Therefore, microalgae/cyanobacteria, being photoautotrophic, prove to have an edge over heterotrophic bacteria. They have minimal metabolic requirements, such as inorganic nutrients $\left(\mathrm{CO}_{2}, \mathrm{~N}, \mathrm{P}\right.$, etc.) and light, and they can survive under adverse environmental conditions. PHA production under photoautotrophic conditions has been reported from cyanobacteria, the only candidate among prokaryotes, and few of the eukaryotic microalgae. However, an efficient cultivation system is still required for photoautotrophic PHA production to overcome the limitations associated with (1) stringent management of closed photobioreactors and (2) optimization of monoculture in open pond culture. Thus, a hybrid system is a necessity, involving the participation of microalgae/cyanobacteria and bacteria, i.e., both photoautotrophic and heterotrophic components having mutual interactive benefits for each other under different cultivation regime, e.g., mixotrophic, successive two modules, consortium based, etc. Along with this, further strategies like optimization of culture conditions ( $\mathrm{N}$, P, light exposure, $\mathrm{CO}_{2}$ dynamics, etc.), bioengineering, efficient downstream processes, and the application of mathematical/network modeling of metabolic pathways to improve PHA production are the key areas discussed here. Conclusively, this review aims to critically analyze cyanobacteria as PHA producers and proposes economically sustainable production of PHA from microbial autotrophs and heterotrophs in "hybrid biological system."

Keywords: polyhydroxyalkanoates, photoautotrophic, heterotrophic, mixotrophy, hybrid biological system, twomodule system, petri net 


\section{INTRODUCTION}

Fossil fuel depletion and non-biodegradability of petro-chemical based plastics has created a scenario where we critically need an alternative. Petroleum based plastic has been extensively used worldwide because of their high durability and inexpensive production. But their persistence due to non-biodegradable nature has raised certain serious environmental concerns. Biodegradable plastics are the best "eco-friendly" alternatives of petrochemical based synthetic plastic for protection and sustainable development of the environment (Gill, 2014; Shen et al., 2020). Polyhydroxyalkanoates (PHAs) are the best candidates for this. These are the polymers of hydroxyacids produced by number of microorganisms including bacteria. PHAs have similar properties to petroleum derived synthetic plastics like polypropylene (PP) and it is $100 \%$ biodegradable in environment (Singh et al., 2015; Sharma et al., 2020). Bacteria belonging to a number of genus are reported to have PHA producing abilities. Out of these, Cupriavidus, Pseudomonas, Bacillus, and recombinant Escherichia coli are majorly used for PHA production through microbial fermentation (Singh et al., 2009; Akdoğan and Çelik, 2018; Brojanigo et al., 2020; Kalia et al., 2021). For PHA production, these organisms were able to utilize various substrates including pure (carbohydrates, fatty acids) and agro-industrial biowaste (Pea Shells, Sweet Potato, Whey, Beet molasses) as substrates (Figure 1; Singh et al., 2009, 2015; Kumar et al., 2013; Amaro et al., 2019; Bhatia et al., 2021; Kalia et al., 2021). But PHA production from these heterotrophic bacteria has been quite expensive which is due to the cost of carbon (C) substrates. Approximately $45 \%$ of the production cost is utilized in substrate procurement. Biowastes have been used as an effective resource and have helped substantially in cost reduction of PHA production process (Singh et al., 2015). But still there is a big economical gap in petroleum-based plastic and bioplastic. Autotrophic microorganisms provide a good alternative for economical PHA production having an edge over heterotrophic bacteria in certain aspects related to bioprocess development. Photoautotrophic organisms, e.g., cyanobacteria (collectively referred to "microalgae" along with eukaryotic microalgae in this review), are emerging as a strong contender for this purpose. Microalgae are an extremely diverse group and still have lots of opportunities unexplored (Borowitzka, 2013).

They present a strong candidature as microbial factory for various bioproducts due to their high growth rate, minimal nutrient requirements, low fresh water requirement, and high photosynthetic efficiency through which they can convert inorganic nutrients $\left(\mathrm{CO}_{2}\right)$ into organic reserves, utilizing light as energy source. The organic reserves produced during photosynthesis can then be further processed to PHA in these cells itself or can be used as feed for other microorganisms. However, autotrophic cultivation also possesses its limitations such as (1) stringent management of closed photobioreactors and (2) optimization of monoculture in open pond culture. Alternatively, bioprocess in which both autotrophic and heterotrophic microorganisms/cultivation can be used may utilize the resources optimally and helps in improving the economy of bioprocess. Thus, in this review we will discuss cyanobacteria as PHA-producing microbial factories, their potential, and challenges and analyze the perspectives of adopting a hybrid system involving both photoautotrophic and heterotrophic components so that their interactive relationship benefits the bioprocess system. Such hybrid system can be exploited under different cultivation regime, e.g., mixotrophic, successive two modules, consortium based, etc. PHA production from cyanobacteria has been reported to be affected by factors like culture conditions: $\mathrm{N}, \mathrm{P}$, light exposure, $\mathrm{CO}_{2}$ dynamics, etc. In addition to that other factors like two-stage (growth and PHA accumulation) processes, metabolic inhibitors for other pathways and bioengineering have also been reported to have a positive impact on PHA production (Sharma et al., 2007; Bhati and Mallick, 2012, 2015, 2016; Kamravamanesh et al., 2017; Troschl et al., 2018). A new promisingly arising field is the application of mathematical/network modeling in this field which has increasingly been adopted to improve PHA production (Novak et al., 2015; Pillai et al., 2019). Here, we propose another tool "Petri Net" and its application in metabolic pathway or bioprocess modeling to improve PHA production.

\section{MICROALGAE AS PHA MICROBIAL FACTORY}

Considered among the fastest growing autotrophic organisms, microalgae are the global primary biomass producers having the ability to fix atmospheric $\mathrm{CO}_{2}$ utilizing solar energy. With the ability to utilize minimal or readily available material, i.e., inorganic nutrients $\left(\mathrm{CO}_{2}\right)$, water, sunlight, wastewater, and having high photosynthetic efficiency, they are the strong candidate as "microbial factory" for the production of various bioproducts (Rahman et al., 2013, 2014; Singh and Mallick, 2017). This ability of microalgae to grow in adverse environment is demonstrated in different studies reporting their cultivation in urban wastewater, swine waste, dairy manure, cattle residues, and poultry litter (PL) (Olguín et al., 2003; Mulbry et al., 2008; Ansari and Fatima, 2019). A vast variety of high value natural products, e.g., pigments, carotenoids, proteins, enzymes, sugars, fatty acids, polysaccharides, phycobilins, sterols, vitamins, and many other unusual bioactive compounds, are produced by microalgae (Olaizola and Huntley, 2003; Ratledge, 2004; Singh et al., 2005; Mendes et al., 2009; Borowitzka, 2013; Kamravamanesh et al., 2018b). They don't need specialized fertile land and large freshwater supply and can be grown on ponds. Thus, microalgal biomass is ideal for PHA production and provides a low-cost economical bioprocess system (Rahman et al., 2014). Among them, only few eukaryotic algae are reported for PHA production, e.g., Chlorella (Roja et al., 2019). But cyanobacteria are taking the lead in this field (Carpine et al., 2015, 2017). Cyanobacteria are one of the largest bacterial group which are aquatic and photosynthetic known to be one of the oldest microorganisms and first photoautotrophic on earth. Thus, they played a vital role in the evolution of life creating an oxygenrich environment and still are contributing to the carbon/oxygen cycle globally. Presence of phycocyanin pigment in them imparts them the characteristic blue-green color, and thus, they are 


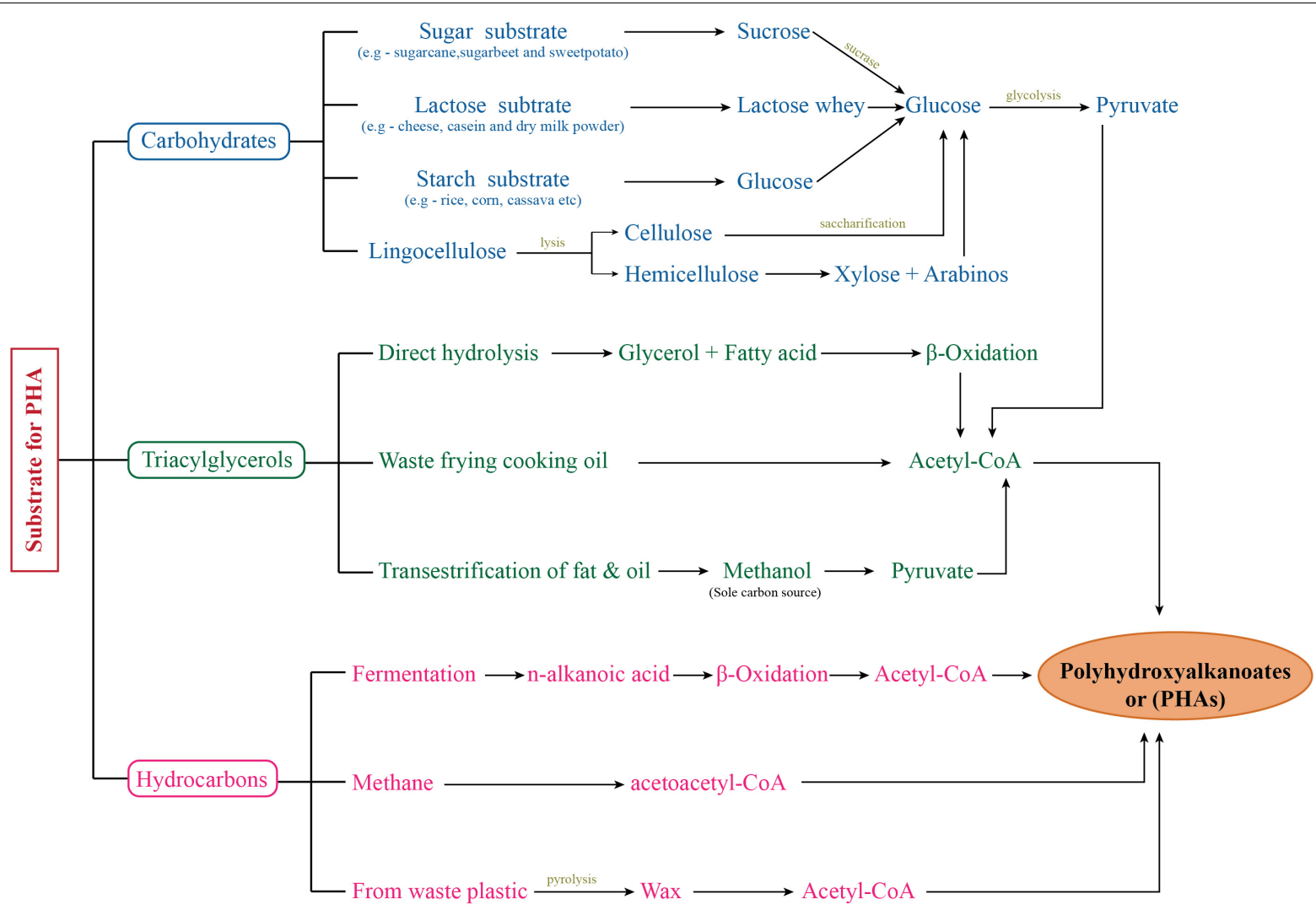

FIGURE 1 | Flow chart showing PHA production from diverse substrates.

known as blue-green algae. Fermentative PHA production is well known from heterotrophic bacteria. Similarly, most cyanobacteria also have the potential, although species specific even within same genera, to produce PHAs as intracellular carbon reserve. Like in heterotrophic bacteria, here also PHA is accumulated under nutrient (e.g., nitrogen and phosphorus) limiting conditions (Kaewbai-ngam et al., 2016). Such studies have reported the PHA production being influenced by various factors, e.g., nutrient availability, culture cultivation parameters ( $\mathrm{pH}$, light-dark cycles, temperature, gas $/ \mathrm{CO}_{2}$ flow), growth phase, and stationary phase duration (Sharma and Mallick, 2005a,b; Panda et al., 2006; Wagner et al., 2016; Troschl et al., 2017, 2018). In addition to this, microalgae can achieve wastewater remediation process along with PHA production through the assimilation of phosphorus and nitrogen as growth nutrients (Rahman et al., 2013). It is interesting to note that the microalgae grown in closed laboratory photobioreactor, open ponds, or in wastewater can achieve higher biomass economically. Thus, in addition to using this biomass as microbial factory for PHA production, this can also be harvested and processed for further utilization as substrate by other heterotrophic bacteria (Rahman et al., 2014). Similar to heterotrophic bacteria, along with PHAs other polymer reserves have also been reported in cyanobacteria, glycogen being the most significant of them (Kumar and Kim, 2018). It is interesting to note that in 1966 the first report of PHA production by cyanobacteria was documented for heterotrophic PHA production in a Chlorogloea fritschii with acetate as C-source; however, photoautotrophic PHA production was soon reported thereafter in 1971 in Gloeocapsa strain 6501 (Kamravamanesh et al., 2018a). Mixotrophy and chemoheterotrophy cultivation, favored over photoautotrophy, have also been documented in various studies (Wu et al., 2001; Sudesh et al., 2002; Sharma and Mallick, 2005b; Panda et al., 2006; Wagner et al., 2016).

\section{PHA BIOSYNTHESIS}

Polyhydroxyalkanoates production under heterotrophic microbial fermentative process has been explained quite extensively with number of researchers in this field. It is well known that the classical polyhydroxybutyrate (PHB) biosynthetic pathway has three basic steps catalyzed by three distinct enzymes: (1) condensation of two acetyl-CoA molecules forming one acetoacetyl-CoA catalyzed by $p h a A$ encoded $\beta$-ketothiolase, (2) reduction of acetoacetyl-CoA by phaB encoded NADPH-dependent acetoacetyl CoA dehydrogenase, and (3) polymerization of 3-hydroxyacid (3HA) units, i.e., (R)-3-hydroxybutyryl-CoA by phaC encoded PHA synthase. In addition to this basic pathway, 3-HA units can also be provided to PHA synthase (PhaC) by other secondary pathways involving methylmalonyl CoA pathway, de novo fatty acid synthetic 
pathway, and fatty acid $\beta$-oxidation pathway. As evident, PHA synthase plays a central and critical role in PHA biosynthesis (Singh et al., 2009, 2015). Heterotrophic bacteria are well studied and explained to have three classes of PHA synthase having specificity to substrate (3-HA) C-chain length. These include Class I PhaC (scl-3HA), Class II PhaC (mcl-3HA), Class III PhaEC with two subunits (EC) (scl-3HA), and Class IV PhaRC with two subunits (RC) (scl-3HA). Based on the presence of these enzymes, a wide range of substrates including sugars (glucose, fructose, sucrose, maltose, and lactose), starch, glycerol, FAs and its derivatives, methanol, lignin, agricultural, industrial, and dairy by-products have been reported as potential substrates for PHA production (Kumar et al., 2019; Bhatia et al., 2021; Kalia et al., 2021). With the addition of different substrates combinations, precursor substrates, adopting different feeding regime PHA compositions and content have been observed to improve (Kumar et al., 2013, 2014; Singh et al., 2015; Ray and Kalia, 2017). Figure 1 summarizes the PHA production by different bacteria on a wide range of substrates.

However, in cyanobacteria which can adapt for both photoautotrophic and heterotrophic cultivation, biosynthetic pathways for the utilization of exogenously provided $\mathrm{C}$ sources are more or less similar with the three basic steps discussed above. It is important to note that most of the information for PHA biosynthesis in cyanobacteria has been gained based on studies done on Synechocystis sp. PCC 6803. Here, synthase enzyme has two subunits PhaEC. Thus, PHA synthase in cyanobacteria belong to the type-III PHA synthases. Genes encoding the enzyme PhaA and PhaB are reported to be arranged in one operon and genes for $\mathrm{PhaE}$ and PhaC are arranged in one operon. Therefore, till now only SCL-PHAs are reported so far in the cyanobacterial species (Hai et al., 2001). Presence of a type-III PHA synthase has also been reported in Synechococcus sp. strains MA19 and PCC 6715, Chlorogloeopsis fritschii PCC 6912, Anabaena cylindrica SAG 1403-2, Cyanothece sp. strains PCC 7424, PCC 8303 and PCC 8801, and Gloeocapsa sp. strain PCC 7428. However, since cyanobacteria is a diverse group, the presence of other types of PHA synthase in them is still unclear and presents a great opportunity in near future (Troschl et al., 2017).

While in autotrophic cultivation of cyanobacteria $\mathrm{CO}_{2}$, the C-source was fixed in Calvin-Benson-Bassham (CBB) cycle with the help of ribulose-1, 5-bisphosphate carboxylase/oxygenase (RuBisCO). RuBisCO has higher efficiency for $\mathrm{CO}_{2}$ than $\mathrm{O}_{2}$ and is known to be responsible for assimilation of $90 \%$ of the carbon present in biomass on earth. Atmospheric $\mathrm{CO}_{2}$ is transported across the wall with the help of inorganic carbon $(\mathrm{Ci})$ transporters, thus helping to maintain local carbon concentration for RuBisCO. The output of the Calvin cycle, glyceraldehyde3-phosphate after its conversion to 3-phosphoglycerate (PGA), can then enter into any of the three pathways for sugar metabolism, i.e., Entner-Doudoroff (ED) pathway, glycolysis, pentose phosphate pathway, and be finally converted to acetyl-CoA to be used in PHA synthetic pathway (Singh and Mallick, 2017; Figure 2).

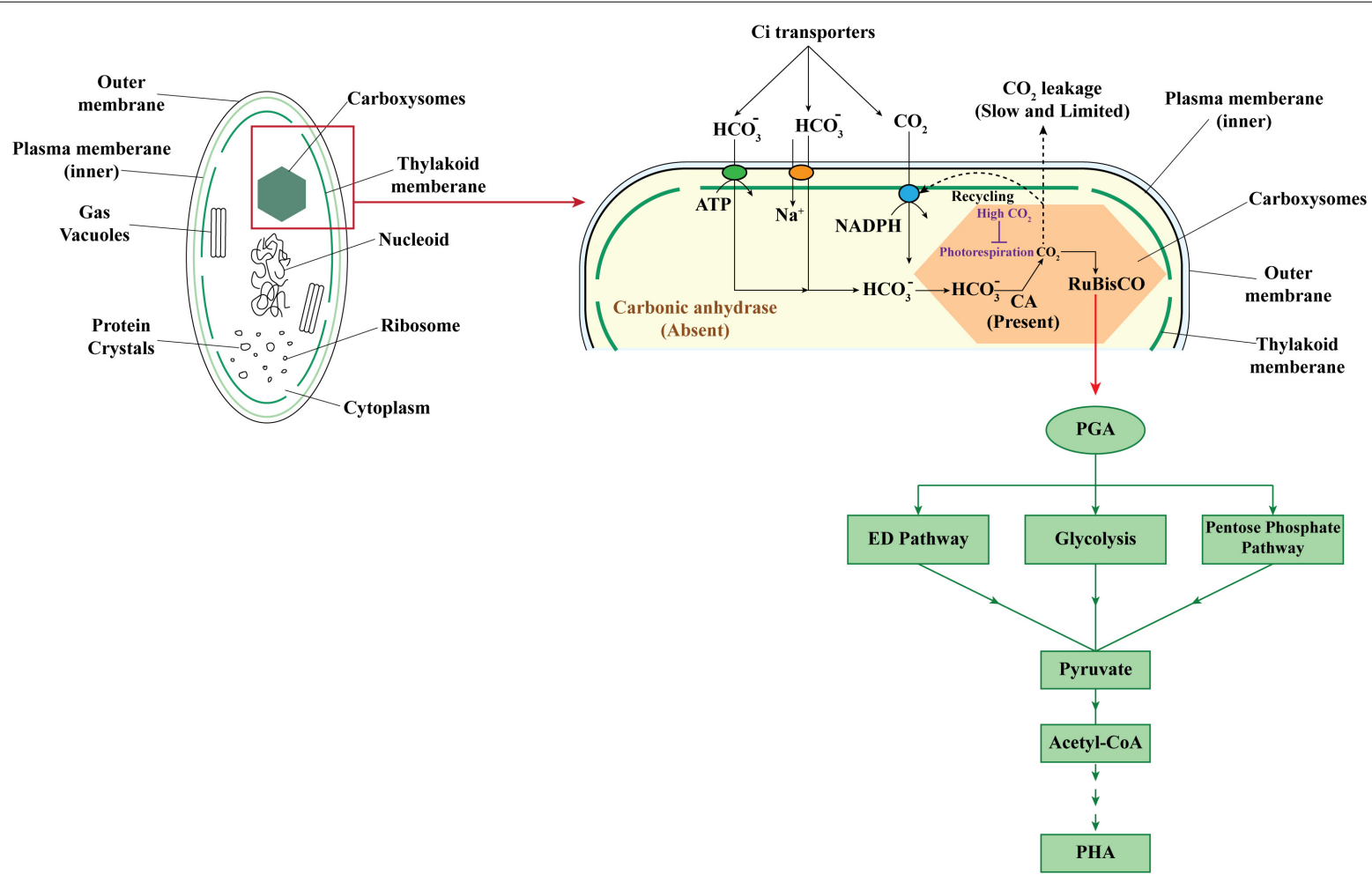

FIGURE 2 | Carbon concentrating mechanism in cyanobacteria for $\mathrm{CO}_{2}$ fixation and further conversion to $\mathrm{PHA}$. 
PHA PRODUCTION IN CYANOBACTERIA

A number of bacteria under this group are reported so far for PHA production majorly including the genus Nostoc, Arthrospira, Synechocystis, and Synechococcu. Here the maximum yield varied from 1 to $78 \%$ depending on the cultivation conditions (Table 1). Invariably, PHA production was seen under nitogen $(\mathrm{N})$ or phosphorus $(\mathrm{P})$ limitation and during late exponential or stationary phase.

\section{Nostoc}

Nostoc is a diverse group of terrestrial as well as aquatic filamentous cyanobacteria occurring around freshwater sources. Since the first report of PHB production that was $8.6 \%$ of cdw by Nostoc muscorum under photoautotrophic conditions in 2005, number of species have been reported for PHA production under phosphate and nitrogen limitation (Sharma and Mallick, 2005a). Later, PHB content up to $19.27 \%$ with $N$. ellipsosporum and $22 \%$ with $N$. muscorum was reported under photoautotrophic conditions (Panda et al., 2005; Martins et al., 2017). Diverting the flux toward PHB production pathway by using metabolic inhibitors carbonylcyanide $m$-chlorophenylhydrazone (CCCP) and dicyclohexylcarbodiimide (DCCD) resulted in PHB accumulation increment up to 21 and $17 \%$ from an initial PHB content of $8.5 \%$ of dry weight, respectively (Mallick et al., 2007). Sharma and Mallick (2005a,b) have reported the effect of culture conditions in improving the PHB production where it could be improved to $35 \%$ under mixotrophic condition with $0.4 \%$ glucose and acetate while a further improvement to $40-43 \%$ with gas exchange limitation under mixotrophy and chemoheterotrophy with $0.4 \%(\mathrm{w} / \mathrm{v})$ acetate. Highest PHB production by $N$. muscorum was obtained up to $145.1 \mathrm{mg} / \mathrm{L}$ ( $16.6 \%$ of $\mathrm{cdw}$ ) with $1 \%$ glucose and $1 \%$ acetate under phosphate starved conditions and $\mathrm{CO}_{2}$ supply (Haase et al., 2012). In addition to nutrient limitation and mixotrophy/heterotrophy, reduction in dark period, i.e., optimizing the light-dark cycle also, has a positive impact on $\mathrm{PHB}$ production as observed on N. muscorum using response surface methodology (Sharma et al., 2007).

TABLE 1 | PHA production from cyanobacteria under different cultivation conditions (I): Nostoc, Arthrospira, Synechocystis, and Synechococcus.

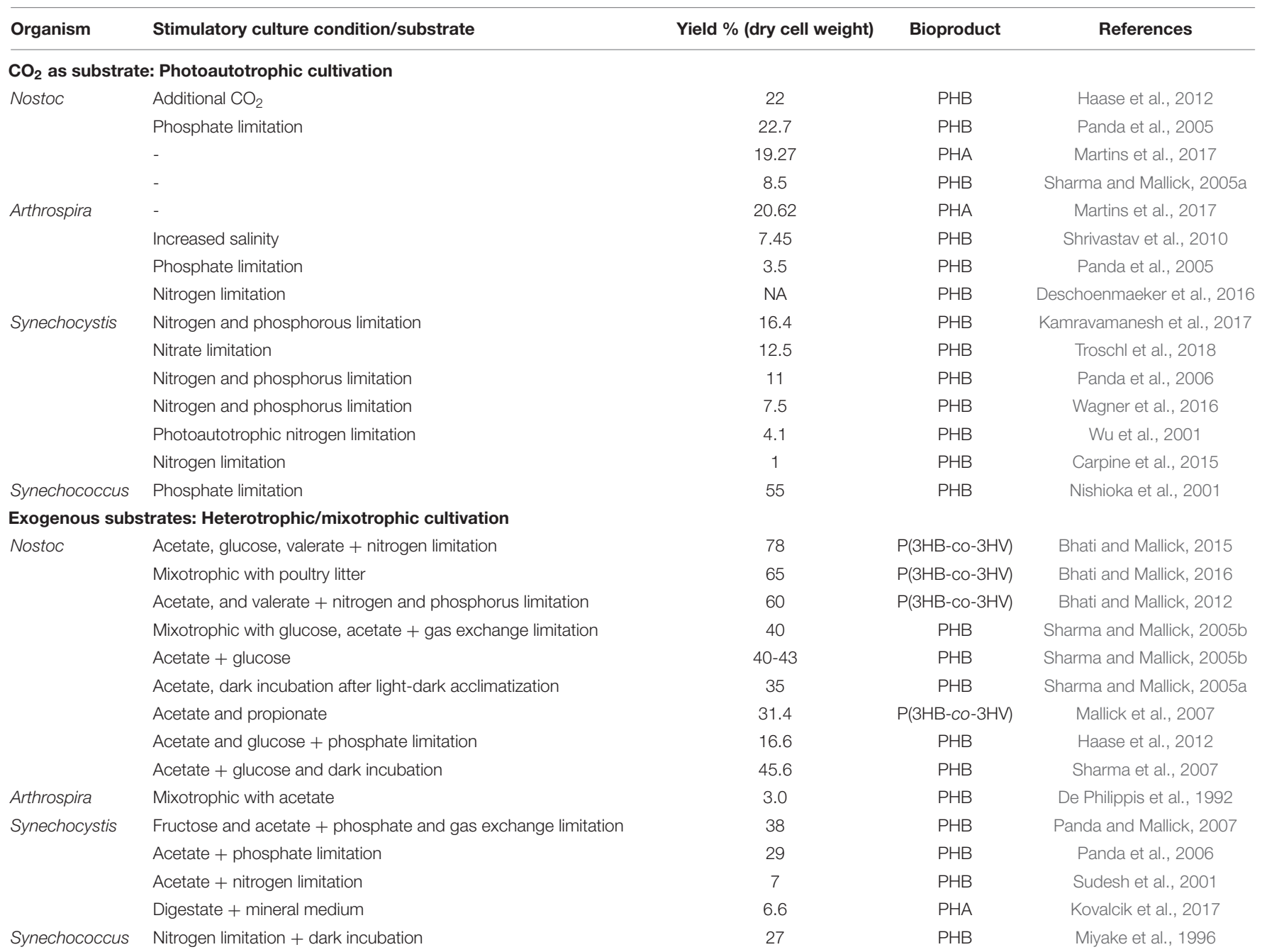


It is interesting to note that PHA copolymer poly(3-hydroxybutyric acid-co-3-hydroxyvaleric acid), $\mathrm{P}(3 \mathrm{HB}-\mathrm{co}-3 \mathrm{HV})$, production has also been reported from Nostoc but that is possible only under mixotrophic or heterotrophic condition with supplementation of propionate or valerate in culture medium. Reports have shown $\mathrm{P}(3 \mathrm{HB}-\mathrm{co}-3 \mathrm{HV})$ production on addition of these precursor substrates up to 28.2-31.4\% (Mallick et al., 2007) and 58-60\% of cdw under nitrogen and phosphate limitation, respectively, which further improved to a highest content of $78 \%$ of cdw under heterotrophic conditions (Bhati and Mallick, 2012, 2015). Poultry litter was used as nutrient supplement at the rate $10 \mathrm{~g} / \mathrm{L}$ in culture along with glucose, acetate, valerate, and $\mathrm{CO}_{2}$ and resulted in the production of $\mathrm{P}(3 \mathrm{HB}-\mathrm{co}-3 \mathrm{HV})$ copolymer yield of $774 \mathrm{mg} \mathrm{L}-1$ (65-70\% of dry cell wt.) (Bhati and Mallick, 2016). Notably, biomass achieved with Nostoc was not very high with yield around $1 \mathrm{~g} / \mathrm{L}$ in most cases, and PHA accumulation in biomass was seen in late exponential phase.

\section{Arthrospira}

Arthrospira, earlier also known as Spirulina, are a type of filamentous bacteria found in alkaline (salt) lake but can be grown in freshwater also. Arthrospira at present is mainly cultivated as food supplement due to its protein and vitamin rich content. But it is a strong candidate to be used for economical PHA production due to the fact that it shows high growth rate with less water requirement. As reported, Arthrospira can achieve 5000-15000 tons dry weight production per year (Spolaore et al., 2006; Lu et al., 2011). The requirement of high alkalinity for its cultivation renders the culture free from other common contaminants. As a result, it can very well be used to maintain a stable and high biomass culture in open ponds. Spirulina platensis is one of the commonly explored species for $\mathrm{PHB}$ production (Panda et al., 2005). Ever since the first report of PHB production in 1982 which was achieved up to $6 \% \mathrm{cdw}$, there has been no significant improvement in PHA production under photoautotrophic conditions. Different strategies have been employed to improve the yield. PHB yield improvement was seen with nitrogen starvation (Deschoenmaeker et al., 2016), phosphate limitation (3.5\% of cdw) (Panda et al., 2005), acetate supplement (2.5-3\% of cdw) (De Philippis et al., 1992) increased salinity (14.7\%) (Shrivastav et al., 2010). Highest yields were obtained with Spirulina sp. LEB 18 which produced $1.48 \mathrm{~g} / \mathrm{L} / \mathrm{d}$ PHB in $15 \mathrm{~d}$ equivalent to $20.62 \%$ of cdw (Martins et al., 2017). As evident, improvement in the yield of PHA production is the major issue related to Arthrospira and Mixotrophic or heterotrophic culture, and condition optimization has helped and can help further to improve the yields.

\section{Synechocystis and Synechococcus}

Synechocystis and Synechococcus are the genus of small-sized cyanobacteria found in both fresh and salt water. PHB production from Synechocystis was observed in 2001 where a yield of $4.1 \%$ was obtained under nitrogen-starved conditions ( $\mathrm{Wu}$ et al., 2001). In this study, mixotrophic cultivation with glucose led to increase in biomass but not PHB yield (\% of cdw). Here, the yield was improved to 9.5 and $15.2 \%$ of $\mathrm{cdw}$ under nitrogen limitation and $11.2 \%$ under phosphorus depletion in comparison to yield of $4.5 \%$ of $\mathrm{cdw}$ in balanced culture cultivation (Panda et al., 2006; Panda and Mallick, 2007; Wu et al., 2020). Samantaray et al. (2011) reported that heterotrophic cultivation with $0.4 \%$ acetate under dark incubation could improve the yield to $22 \%$ of cdw which was further improved to $38 \%$ of $\mathrm{cdw}$ when the stationary phase culture was subjected to phosphate and gas exchange limitation in the presence of acetate $(0.4 \%)$ and fructose (0.4\%) (Panda and Mallick, 2007). Till now Synechocystis PCC6803 is the most widely used strain for PHA production (Carpine et al., 2015). Closely related genus Synechococcus are also reported in literature for PHA production. Synechococcus sp. MA19, a thermophilic cyanobacterium which was a natural inhabitant of wet volcanic rock surface in Japan, produced PHB utilizing $\mathrm{CO}_{2}$ up to $27 \%$ (w/w) (Miyake et al., 1996). The yields from this strain in photoautotrophic cultivation was further improved to $55 \%$ (dcw) amounting to $2.4 \mathrm{~g} / \mathrm{L}$ under phosphate limitation. This is the highest PHA production reported so far from cyanobacteria under photoautotrophic conditions (Nishioka et al., 2001). S. salina was also reported to produce $7.5 \%$ of $\mathrm{PHB}$ which was further used after hydrothermal liquefaction for bio-oil production (Wagner et al., 2016). In another report it produced comparable yields of $4.8-9 \%$ of cdw reaching up to $2.0 \mathrm{~g} / \mathrm{L}$ in 21 days of incubation in a large tubular photobioreactor with medium circulated, $\mathrm{pH}$ controlled through $\mathrm{CO}_{2}$ flow, artificial illumination, and controlled temperature. Here, nitrogen limitation and illumination were observed to improve the PHA production while mixotrophy by the addition of acetate did not help due to contamination (Kovalcik et al., 2017). There has been not much reports for PHA production by Synechococcus sp., and hence, it leaves a lot of scope to try mixotrophic or heterotrophic cultivation to improve the production.

In addition to the above-mentioned genus that are majorly used for PHA production, other genus have also been reported to have PHA producing abilities. These genera include Chlorogloea fritschii, Gloeocapsa sp., Oscillatoria limosa, Gloeothece sp. PCC 6909, Aulosira sp., and Calothrix (Stal et al., 1990; Hai et al., 2001; Samantaray et al., 2011; Kaewbai-ngam et al., 2016; Table 2). Chlorogloeopsis fritschii PCC 6912, which is a thermophilic cyanobacteria, was reported to have $6 \%$ of $\mathrm{PHB}$ in its dried biomass (Hai et al., 2001), while Brevibacillus invocatus MTCC 9039 had PHB up to $3 \%$ of $\mathrm{cdw}$ accumulated in its stationary phase (Sankhla et al., 2010). Samantaray and Mallick (2012) reported the production of $\mathrm{PHB}$ simultaneously along with wastewater treatment in a biological recirculatory system by $\mathrm{N}_{2}$ fixing cyanobacterium Aulosira fertilissima. This bacteria was also reported to produce $77 \%$ PHB under phosphate deficiency with $0.5 \%$ acetate and improved to $85 \%$ of cdw of $\mathrm{PHB}$ with $0.26 \%$ citrate, $0.28 \%$ acetate, and $5.58 \mathrm{mg} / \mathrm{L} \mathrm{K}_{2} \mathrm{HPO}_{4}$ for an incubation period of 5 days (Samantaray et al., 2011). Similarly under nitrogen limitation, Calothrix scytonemicola TISTR 8095 could produce $25 \%$ of $\mathrm{cdw}(356.6 \mathrm{mg} / \mathrm{L}) \mathrm{PHB}$ in 44 days (Kaewbai-ngam et al., 2016). Anabaena cylindrica, a filamentous cyanobacterium, could produce $2 \%$ of cdw $\mathrm{PHB}$ while $\mathrm{P}(3 \mathrm{HB}-$ co-3HV) was produced on supplementation of valerate and propionate (Lama et al., 1996). 
TABLE 2 | PHA production from cyanobacteria under different cultivation conditions (II).

\begin{tabular}{|c|c|c|c|c|}
\hline Organism & Substrate and culture condition & Yield \% (dcw) & Bioproduct & References \\
\hline \multicolumn{5}{|c|}{$\mathrm{CO}_{2}$ as substrate: Photoautotrophic cultivation } \\
\hline Aulosira fertilissima & $\mathrm{CO}_{2}+$ waste water & $34.8\left(41 \mathrm{~g} / \mathrm{m}^{2}\right)$ & $\mathrm{PHB}$ & Samantaray et al., 2011 \\
\hline Calothrix scytonemicola & Nitrogen lim. & 25.2 & $\mathrm{PHB}$ & Kaewbai-ngam et al., 2016 \\
\hline Anabaena sp. & - & 2.3 & $\mathrm{PHB}$ & Gopi et al., 2014 \\
\hline Phormidium & - & 2.3 & $\mathrm{PHB}$ & Gopi et al., 2014 \\
\hline \multicolumn{5}{|c|}{ Exogenous substrates: Heterotrophic/mixotrophic cultivation } \\
\hline \multirow[t]{5}{*}{ Aulosira fertilissima } & Waste water + citrate + acetate & $87.22\left(92 \mathrm{~g} / \mathrm{m}^{2}\right)$ & $\mathrm{PHB}$ & Samantaray et al., 2011 \\
\hline & Acetate + phosphorous limitation & 77 & $\mathrm{PHB}$ & Samantaray and Mallick, 2012 \\
\hline & Fructose + valerate supplementation/phosphate deficiency & $62-77$ & $\mathrm{P}(3 \mathrm{HB}-\mathrm{CO}-3 \mathrm{HV})$ & Samantaray and Mallick, 2014 \\
\hline & Acetate + citrate & 66 & PHB & Samantaray and Mallick, 2012 \\
\hline & Citrate + phosphate limitation + dark & 51 & $\mathrm{PHB}$ & Samantaray and Mallick, 2012 \\
\hline Chlorogloeopsis fritschii & Mixotrophic with acetate & 6.2 & PHB & Hai et al., 2001 \\
\hline Scytonema geitleri & Acetate & 7.12 & $\mathrm{PHB}$ & Singh et al., 2019 \\
\hline \multirow[t]{2}{*}{ Anabaena cylindrica } & Acetate & 2 & $\mathrm{PHB}$ & Lama et al., 1996 \\
\hline & Acetate + propionate & & $\mathrm{PHB}$ & Lama et al., 1996 \\
\hline
\end{tabular}

\section{Recombinant Cyanobacteria}

Genetic engineering to modify microorganisms toward specific needs or property has been a well exploited practice in case of prokaryotic research and development. Since prokaryotes are relatively easy to manipulate due to simple genetic makeup in comparison to algae and plants, cyanobacteria also possess such attributes. Spontaneous transformability and short generation time have made Synechocystis sp. PCC6803 as the best studied model cyanobacterium not only for PHA production but other cyanobacteria related researches too. Moreover, Synechocystis sp. PCC6803 also has the honor of being the first photoautotrophic organism to have the complete genome sequenced in 1997 and first recombinant cyanobacteria used for PHA production (Wilde and Dienst, 2011; Troschl et al., 2017; Kamravamanesh et al., 2018a,b). As observed in studies discussed above, recombinant cyanobacteria also showed improvement with nutrient limitation and mixotrophic cultivation (Table 3). PHA biosynthesis can be improved by introducing multicopies of heterologous PHA synthase gene up to $11 \mathrm{wt} \%$ of the cdw (Sudesh et al., 2001). The ADP-glucose pyrophosphorylase gene (agp) was inserted with an erythromycin resistance cassette and under nitrogen depletion, photoautotrophic PHB production was up to $14.6 \%$ which improved under mixotrophic cultivation with acetate up to $18.6 \%$ (Wu et al., 2002). Inactivation of Thesll0783 gene by of kanamycin/bleomycin resistance cassettes and cultivation under nitrogen depletion indicated the importance of Thesll0783 gene in PHB production (Schlebusch and Forchhammer, 2010). The native SigE gene was overexpressed into Synechocystis, to control changes in sugar catabolism related to glycogen pathway which resulted in $1.4 \%$ of cdw phototrophically (Osanai et al., 2013). Similarly, overexpression of PHA biosynthetic operon from Microcystis aeruginosa NIES-843 in Synechocystis, resulted in $7 \%$ of cdw photoautotrophic PHB production under nitrogen depletion (Hondo et al., 2015). In another report, out of the four native genes chosen for overexpression (phaAB, phaEC, and phaABEC), maximum PHB content of $26 \%$ of cdw was achieved under nitrogen depletion with $p h a A B$ overexpression as compared to $9.5 \%$ of cdw in wild-type which further improved to $35 \%$ under mixotrophic conditions with supplementation of $0.4 \%$ acetate under nitrogen depletion (Khetkorn et al., 2016). Although not PHA, Wang et al. (2013) have reported 3-hydroxybutyrate by phaEC inactivated Synechocystis having heterologous expression of thioesterase gene (tesB) from E. coli and phaAB gene from Cupriavidus necator $\mathrm{H} 16$ under photoautotrophic utilizing $\mathrm{CO}_{2}$. Overexpression of PHA synthase from Chromobacterium sp. USM2 (phaC $\left.C_{C s}\right)$, acetoacetyl-CoA synthase from Streptomyces sp. CL190 (nphT7 $\left.7_{s s}\right)$, and C. necator acetoacetyl-CoA reductase $\left(p h a B_{C n}\right)$ genes under the control of the light-inducible $p s b A I I$ promoter under direct photosynthesis produced $14 \% \mathrm{cdw}$ yield, among the best, under photoautotrophic cultivation and were observed to further improve to $41 \%$ on addition of acetate $0.4 \%$ (Lau et al., 2014). Recently, a strategy of increasing acetyl-CoA level by inducing deletions of phosphotransacetylase (Pta) and acetyl-CoA hydrolase (Ach) and the expression of a heterologous phosphoketolase (XfpK) from Bifidobacterium breve with $\mathrm{CO}_{2}$ as feed produced $12 \%$ of $\mathrm{cdw}(232 \mathrm{mg} / \mathrm{L})$ (Carpine et al., 2017). Optimization of acetyl CoA reductase binding site with $\mathrm{CO}_{2}$ produced $1.84 \mathrm{~g} / \mathrm{L} \mathrm{PHB}$ with productivity of $263 \mathrm{mg} / \mathrm{L} / \mathrm{d}$ (Wang et al., 2018).

Genetic manipulations have also been successfully employed in Synechococcus. Synechococcus sp. PCC7942 having PHB synthesizing genes from Alcaligenes eutrophus produced 3.01\% of $c d w$ PHB under photoautotrophic and nitrogen-starved conditions which was further improved $25.6 \%$ of $\mathrm{cdw}$ on supplementation of acetate under nitrogen-starvation (Takahashi et al., 1998). Recombinant cyanobacteria Synechococcus sp. PCC7002 recA null mutation with the $E$. coli recA gene achieved 52\% of cdw PHA from carbon dioxide in Antibioticsfree cultivation (Akiyama et al., 2011). Synechococcus PCC7942 having heterologous expression of C. necator PHA operon showed improved PHA accumulation, i.e., from 3 to $25 \%$ of $c d w$ (Drosg et al., 2015) and introduction of GABA shunt with $\mathrm{CO}_{2}$ feed led to PHA yield of $4.5 \% \mathrm{cdw}$ (Zhang et al., 
TABLE 3 | PHA production from recombinant cyanobacteria under different cultivation conditions.

\begin{tabular}{|c|c|c|c|c|}
\hline Organism & Recombinant factor/Culture media & $\begin{array}{l}\text { Yield \% (dry cell } \\
\text { weight) }\end{array}$ & Biopolymer & References \\
\hline \multicolumn{5}{|c|}{$\mathrm{CO}_{2}$ as substrate: Photoautotrophic cultivation } \\
\hline \multirow[t]{9}{*}{ Synechocystis } & Random UV mutagenesis & 37 & $\mathrm{PHB}$ & Kamravamanesh et al., 2018a \\
\hline & Optimized ribosome binding site for phaB1 & 35 & $\mathrm{PHB}$ & Wang et al., 2018 \\
\hline & $\begin{array}{l}\text { Overexpression of native phaA and phaB } \\
\text { Nitrogen deprivation }\end{array}$ & 26 & $\mathrm{PHB}$ & Khetkorn et al., 2016 \\
\hline & $\begin{array}{l}\text { Overexpression of the sigma factor sigE } \\
\text { Nitrogen limitation }\end{array}$ & 25 & $\mathrm{PHB}$ & Osanai et al., 2013 \\
\hline & agp gene-deletion-mutant & 14.9 & $\mathrm{PHB}$ & Wu et al., 2002 \\
\hline & $\begin{array}{l}\text { Overexpression phaC } C s, n p h T 7_{S s} \text {, and } p h a B_{C n} \text { under the control of the } \\
\text { psbAll promoter } \\
\text { Increased } \mathrm{CO}_{2}\end{array}$ & $14-16 \%$ & $\mathrm{PHB}$ & Lau et al., 2014 \\
\hline & xfpk overexpression in double pta and ach mutant & 12 & $\mathrm{PHB}$ & Carpine et al., 2017 \\
\hline & Overexpression of PHA biosynthetic operon from Microcystis aeruginosa & 7.0 & $\mathrm{PHB}$ & Hondo et al., 2015 \\
\hline & $\begin{array}{l}\text { Knockout mutant of the sll0783 gene } \\
\text { Nitrogen limitation }\end{array}$ & NA & $\mathrm{PHB}$ & Schlebusch and Forchhammer, 2010 \\
\hline \multirow{2}{*}{ Synechococcus } & $\begin{array}{l}\text { Pha genes in complemented cyanobacterial recA null mutant with the } \\
\text { E. coli recA } \\
\text { Nitrogen limitation }\end{array}$ & 52 & $\mathrm{PHB}$ & Akiyama et al., 2011 \\
\hline & PHA biosynthesis genes from C. necator & 1.85 & $\mathrm{PHB}$ & Takahashi et al., 1998 \\
\hline \multicolumn{5}{|c|}{ Exogenous substrates: Heterotrophic/mixotrophic cultivation } \\
\hline \multirow[t]{5}{*}{ Synechocystis } & $\begin{array}{l}\text { Overexpression phaC } C_{C s}, n p h T 7_{S s} \text { and } p h a B_{C n} \text { under the control of the } \\
\text { psbAll promoter } \\
\text { Acetate + gas exchange limitation }\end{array}$ & 41 & $\mathrm{PHB}$ & Lau et al., 2014 \\
\hline & $\begin{array}{l}\text { Overexpression of native phaA and phaB } \\
\text { Acetate and nitrogen } \\
\text { Limitation }\end{array}$ & 35 & $\mathrm{PHB}$ & Khetkorn et al., 2016 \\
\hline & $\begin{array}{l}\text { agp gene-deletion-mutant } \\
\text { Acetate }\end{array}$ & 18.6 & $\mathrm{PHB}$ & Wu et al., 2002 \\
\hline & $\begin{array}{l}\text { PHA biosynthetic genes of } C \text {. necator } \\
\text { Acetate and nitrogen limitation }\end{array}$ & 11 & $\mathrm{PHB}$ & Sudesh et al., 2002 \\
\hline & $\begin{array}{l}\text { PHA biosynthetic operon from C. necator } \\
\text { Acetate and nitrogen limitation }\end{array}$ & 11 & $\mathrm{PHB}$ & Sudesh et al., 2001 \\
\hline Synechococcus & $\begin{array}{l}\text { PHA biosynthesis genes from C. necator } \\
\text { Acetate and nitrogen limitation }\end{array}$ & 26 & $\mathrm{PHB}$ & Takahashi et al., 1998 \\
\hline
\end{tabular}

2016). In an interesting report, polymer with 4-hydroxybutyrate (4HB) monomer also, i.e., copolymer $\mathrm{P}(3 \mathrm{HB}-\mathrm{co}-4 \mathrm{HB})$ was produced with the introduction of PHA biosynthetic genes from Chlorogloeopsis fritschii PCC 9212 and $c c m R$ gene deletion in Synechococcus sp. PCC 7002. This study provided PHA content of $\sim 4.5 \%$ of cdw and was an indication of possibility of $\mathrm{P}(3 \mathrm{HB}-$ co-4HB) production in cyanobacteria using light and $\mathrm{CO}_{2}$ (Zhang et al., 2015).

\section{HYBRID BIOLOGICAL SYSTEM}

Although the PHA production in heterotrophic cultivation have attained a significant level as far as the yield per unit feed are concerned. However, still the feed procurement cost is one of the major concerns making it an expensive practice to follow. As discussed till now, it is quite clear that due to the high photosynthetic efficiency, minimal nutrient requirement, high growth per hectare and $\mathrm{CO}_{2}$ sequestering ability, cyanobacteria has gained the attention of researchers in biotechnology across the globe. In addition to that other properties such as no specific agricultural land requirement as compared to plants, efficient waste water utilization are also notably interesting. Possibilities of genetic engineering have added to its popularity providing a novel low cost expression system. Thus, PHA production from cyanobacteria eliminates the factors causing high production cost, i.e., exogenous $\mathrm{C}$ substrates, nutrient maintenance, etc. But, as with any other system photoautotrophic PHA production also has its limitations which need to be addressed while developing a sustainable system. It is quite evident that photoautotrophic cultivation in laboratory photobioreactors are helpful in maintaining monoculture but need continuous illumination which requires high maintenance, thus causing high production cost. In comparison, open pond cultures are economical but maintaining a contamination free monoculture is a challenge. Moreover, the uncertainty due to fluctuation in temperature, $\mathrm{pH}$, light intensity, and $\mathrm{CO}_{2}$ fixation caused by diurnal and seasonal changes leads to less efficient system (Kamravamanesh et al., 2018b).

Thus, the need of the hour is to develop a hybrid biological system that can address the challenges and utilizes the opportunities present in both photoautotrophic and 
heterotrophic cultivation. Various reports have shown that PHA during photoautotrophic cultivation is lower and can be achieved up to 55\% only in Synechococcus sp. (Nishioka et al., 2001). Thus, here we suggest the following cultivation regimes and strategies to improve PHA production.

\section{Mixotrophy}

Invariably in all the cases reported so far mixotrophic cultivation or heterotrophic cultivation have resulted in significant improvement in PHA yields (Sudesh et al., 2002; Sharma and Mallick, 2005b; Panda et al., 2006; Wagner et al., 2016). There has been 2-9-fold improvement in PHA yield (\% of cdw). This suggests a possibility to use photoautotrophic and heterotrophic component (cultivation) in same system. The proposed system having a cyanobacteria as PHA producer may be subjected to photoautotrophic cultivation during day time/light phase followed by the introduction of heterotrophic cultivation during night time/dark phase (Hai et al., 2001; Sharma and Mallick, 2005b; Sharma et al., 2007; Bhati and Mallick, 2016; Kovalcik et al., 2017). During light phase, cyanobacteria will utilize $\mathrm{CO}_{2}$ as carbon source, and in dark phase, exogenous $\mathrm{C}$ sources (glucose, acetate, copolymer precursors, etc.) may be added in media. An alternative improvement takes high biomass growth and lower PHA yield in cyanobacteria under photoautotrophic cultivation under consideration. In this system (Figure 3A), cyanobacteria may be subjected to photoautotrophic conditions during day time/light phase without any N/P limitation to attain high biomass till the late exponential or stationary phase and then subjected to heterotrophic conditions in night time/dark phase under N/P limitations. This may constitute a feast (dark) and famine (light) phase, promoting PHA production in microorganisms.

\section{Photoautotrophic-Heterotrophic Consortium}

The main aim of developing a consortium is to have a more efficient system through the division of labor that gives enhanced accessibility of resources, enhanced productivity, efficient nutrient cycling, community stability and non-competitive partitioning, and distribution of carbon or energy source between members of community based on metabolic functionality. Out of the different interaction aspects, mutualistic relationship is the most widely exploited for numerous biotechnology studies such as bioprocess, biofuel, and other value-added products formation (Bernstein and Carlson, 2012). Photosynthetic consortium having algae and bacteria has been reported for PHA production. Here, PHA production was obtained up to $20-30 \%$ of cdw without oxygen supplementation. In this study the consortium was subjected to feast and famine regime where the PHA production was achieved in feast phase during dark cultivation. During famine phase in illuminated cultivation, accumulated PHA can be oxidized and consumed releasing the reducing equivalents and $\mathrm{CO}_{2}$. The reducing equivalents produced during this famine phase are used in PHA production process in feast phase, while the $\mathrm{CO}_{2}$ released is used by algae for photosynthesis. During photosynthesis, algae released $\mathrm{O}_{2}$ which reduced the aeration requirement and was also used for PHA oxidation. Thus, this study provided an evidence of efficient resource utilization by consortium (Fradinho et al., 2013a,b). Another consortium of microalga Chlorella vulgaris and the bacterium Pseudomonas aeruginosa was developed by Guerra-Renteria et al. (2019) for nitrogen and phosphorus uptake from wastewater. Thus the consortium can be used for organic waste degradation also where oxygen release from algae is utilized by bacteria to degrade organic matter simultaneously $\mathrm{CO}_{2}$ release from the bacteria is utilized by microalgae as raw material to complete photosynthesis. This symbiotic interaction helps to reduce wastewater treatment efforts by natural way. A recent study has reported lichen-associated Pseudomonas having the ability to detoxify and utilize naphthalene and anthracene for energy reserve storage and produce PHA with $3-\mathrm{HHx}$ unit up to 30.62 and $19.63 \%$ of $3-\mathrm{HHx}$, respectively (Nahar et al., 2019). The proposed system has consortium of microalgae/cyanobacteria and bacteria as two components so as to utilize resources under both light and dark phase (Figure 3B).

\section{Two Module System}

Since the PHA yield in fast growing photoautotrophic cultivation, the PHA yields are low. Thus, either the high biomass or the organic products released by them can alternatively be used as substrate itself. Hydrothermal liquefaction (HTL) is the efficient strategy to obtain organic compounds from cyanobacterial

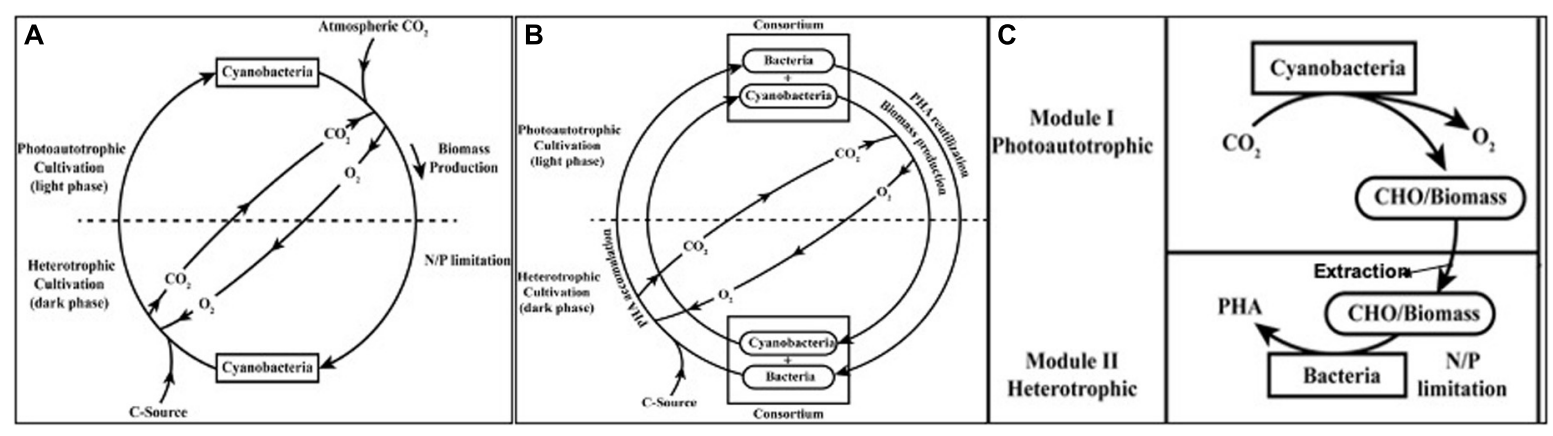

FIGURE 3 | Strategies and culture regime of "hybrid biological system" for PHA production improvement. (A) Mixotrophy; (B) Photoautotrophic-heterotrophic consortium; and (C) Two module system. 
biomass, e.g., propylene and bio oil (biofuel) production was shown from cyanobacterial biomass processed through HTL. This suggested PHB as a feedstock for biorefinery as propylene level was found to be proportional to the accumulated amount of PHB (Wagner et al., 2016). One of the study revealed that microalgae grown in wastewater can be harvested using different methods. The harvested biomass can further be used as a substrate for growth of genetically engineered E. coli and PHB production (Rahman et al., 2014). Using defatted biomass also gives an attractive option as reported by Goo et al. He showed $82 \%$ biopolymer yield using defatted mass of microalgae Dunaliella tertiolecta with different salt concentration (Goo et al., 2013). In a recent report, PHA production was reported in two modules with synthetic mixed culture of Synechococcus elongatus $\operatorname{cscB}$ and Pseudomonas putida cscAB. Here in the first module, Synechococcus elongatus $\operatorname{cscB}$ was cultivated under photoautotrophic condition where it fixes $\mathrm{CO}_{2}$ to convert it into sucrose and release it into culture medium. In the second module, Pseudomonas putida csc AB was used under heterotrophic cultivation to utilize sucrose produced in first module for PHA production under nitrogen limitation (Lowe et al., 2017). The proposed system, depicted in Figure 3C, may have photoautotrophic cyanobacterial growth in one module, and then in second module after the processing of its biomass, it can be utilized by heterotrophic bacteria as substrate for PHA production.

\section{Metabolic Network Modeling}

A number of factors and parameters have been reported in literature those are affecting the growth and PHA production in microalgae. Some of them are temperature, light intensity, $\mathrm{pH}$, salinity, $\mathrm{CO}_{2}$ exchange level, nitrogen level, phosphorous level etc. These factors are more detrimental when operating in a large scale or open pond culture. Even if, we use the above proposed strategies involving the use of consortium or two module system, optimization of these factors and additionally the metabolic interaction of member microorganisms, is a critical step and requires lot of efforts and resource utilization affecting the final performance and efficiency of any bioprocess. In the effort of developing a bioprocess for PHA production we need to have an insight into the enzymatic and metabolic pathways of the PHB biosynthesis. We need to select or manipulate genetically an optimal strain with maximum productivity. In addition to these, other requirements like the selection of inexpensive substrate, culture condition optimization of media, process parameter optimization for large scale production and designing a bioreactor ought to be managed carefully (Troschl et al., 2017). In present research world, mathematical or in silico tools are proving to be a boon in such studies, as these not only can handle integration and combination of large number of parameters or interactive connections to be analyzed but also reduce the time taken for experimental exercises to completely analyze that much number of combinations. Microbial consortia engineering through studying the highly complex interactions between populations and also with environment is increasingly been accepted to have potential to construct sustainable bioprocesses with enhanced metabolic productivity. Mathematical models including differential equations and stochastic methods have been used in microbial ecology modeling (Bernstein and Carlson, 2012). A number of mathematical models used in different studies for PHA production include kinetic, dynamic, cybernetic models (Dias et al., 2008; Jiang et al., 2011; Novak et al., 2015). Flux balance analysis (FBA) or in other words linear programming (LP) based on objective function and constraints is used in multiple studies, e.g., to predict the relative abundance of Desulfovibrio vulgaris (sulfate reducing bacteria) and Methanococcus maripaludis (methanogen) based on the analysis of mutual metabolic exchange between them (Stolyar et al., 2007), dynamic modeling for simulation of two different co-cultures for synergistic co-fermentation of xylose + glucose mixture with ethanol (Hanly and Henson, 2011, 2013), synthetic or semisynthetic co-cultures of E. coli analysis for xylose, and glucose utilization in S. cerevisiae. Another stoichiometric model is the elementary flux mode analysis (EFMA) that includes metabolic pathway network modeling and analysis (Volkova et al., 2020). EFMA has been used to study mass and energy flows through microbial community of a phototrophic, biofilm community (Taffs et al., 2009).

Somehow, majority of mathematical tools are not easy to use for non-mathematical background people. Thus, network-based modeling is a convenient option in such case. Metabolic network modeling-guided strains' design or development is gaining interest and has been used for n-butanol, 1,3-propanediol, glycerol, limolene, and isoprene (Hendry et al., 2020). Genomescale metabolic network reconstructions and constraint-based analyses have been used in number of studies for metabolic modeling (Lee et al., 2020). Similar strategy was used to predict and design a strain that has a force C-flux toward malonyl$\mathrm{CoA}$ for enhanced production of polyketides and biofuels (Xu et al., 2011). Recently, a novel strain design algorithm OptRAM (Optimization of Regulatory and Metabolic Networks) was developed with integrative regulatory and metabolic network modeling. This tool has helped the researchers to identify and design strain for Succinate 2,3-butanediol and ethanol production in yeast (Shen et al., 2019). Similarly, mathematical and metabolic engineering were used for PHA production and recovery process improvement (Novak et al., 2015; Pillai et al., 2019). In another study, analysis and prediction of metabolic flexibility of Candidatus Accumulibacter phosphatis, a phosphate accumulating organism, was done based on redox factor preferences of different oxidoreductase (da Silva et al., 2020).

For network-based modeling, here we propose another tool Petri Net for such analysis. Petri Nets (PN) are directed bipartite graph in with vertices as two disjointed sets, i.e., places and transitions. Arcs connect vertices, i.e., transitions with places and places with transitions. The distribution of tokens, i.e., quantities of particular components over the places corresponds to the state of the modeled system. In biological representation "places" (circles) correspond to biological or chemical components, "Transitions" (rectangles) to processes (e.g., reactions) (Kansal et al., 2015). A transition is active only under certain dynamics and firing rules causing the flow of tokens, i.e., information and tokens are consumed from the input places through the transitions. PN provide a competent method for both 
qualitative (structural topology) and quantitative analysis (token distribution). Snoopy, MARCIE, WoPeD, and Pathway Logic Assistant are some of the tools used for petri net modeling in computational biology (Bartocci and Lio, 2016). Petri Net has the advantage of graphical representation of complex networks which is compatible to computational simulations and is user friendly to a non-mathematical population (Koch, 2015). It has been used to model various biological pathways/processes, e.g., metabolism, signal transduction, gene regulation, protein complex assembly, metabolic disorders for biomedical data prediction, and enzyme kinetic modeling (Koch et al., 2017). Recently, PN are used for modeling of biological pathways (PHA; C3 pathway), networks for processes involved in diagnostics, treatment, and multi drug resistance in tuberculosis (Gupta et al., 2019; Singh and Jha, 2019; Singh et al., 2020).

\section{CONCLUSION}

In spite of having an advantage associated with photoautotrophic metabolism that eliminates the cost attributed to $\mathrm{C}$ substrate, cyanobacteria still have lower yield of photoautotrophic PHA production. However, still a sustainable biological system can be constructed if we can efficiently use the abilities and attributes related to photoautotrophic and heterotrophic PHA production. The proposed hybrid biological system involving mixotrophy, photoautotrophic-heterotrophic consortium and two module

\section{REFERENCES}

Akdoğan, M., and Çelik, E. (2018). Purification and characterization of polyhydroxyalkanoate (PHA) from a Bacillus megaterium strain using various dehydration techniques. J. Chem. Technol. Biotechnol. 93, 2292-2298. doi: $10.1002 /$ jctb. 5572

Akiyama, H., Okuhata, H., Onizuka, T., Kanai, S., Hirano, M., Tanaka, S., et al. (2011). Antibiotics-free stable polyhydroxyalkanoate (PHA) production from carbon dioxide by recombinant cyanobacteria. Bioresour. Technol. 102, 1103911042. doi: 10.1016/j.biortech.2011.09.058

Amaro, T. M., Rosa, D., Comi, G., and Iacumin, L. (2019). Prospects for the use of whey for polyhydroxyalkanoate (PHA) production. Front. Microbiol. 10:992. doi: $10.3389 /$ fmicb. 2019.00992

Ansari, S., and Fatima, T. (2019). Cyanobacterial polyhydroxybutyrate (PHB): screening, optimization and characterization. PLoS One 11:e0158168. doi: 10. 1371/journal.pone.0158168

Bartocci, E., and Lio, P. (2016). Computational modeling, formal analysis, and tools for systems biology. PLoS Comput. Biol. 12:e1004591. doi: 10.1371/journal.pcbi. 1004591

Bernstein, H. C., and Carlson, R. P. (2012). Microbial consortia engineering for cellular factories: in vitro to in silico systems. Comput. Struct. Biotechnol. J. 3:e201210017. doi: 10.5936/csbj.201210017

Bhati, R., and Mallick, N. (2012). Production and characterization of poly (3-hydroxybutyrate-co-3-hydroxyvalerate) co-polymer by a N2-fixing cyanobacterium, Nostoc muscorum Agardh. J. Chem. Technol. Biotechnol. 87, 505-512. doi: $10.1002 /$ jctb. 2737

Bhati, R., and Mallick, N. (2015). Poly (3-hydroxybutyrate-co-3-hydroxyvalerate) copolymer production by the diazotrophic cyanobacterium Nostoc muscorum Agardh: process optimization and polymer characterization. Algal Res. 7, 78-85. doi: 10.1016/j.algal.2014.12.003

Bhati, R., and Mallick, N. (2016). Carbon dioxide and poultry waste utilization for production of polyhydroxyalkanoate biopolymers by Nostoc muscorum Agardh: system along with the optimization of process parameters, and utilization of metabolic network modeling can achieve the required sustainability. Such biological system can provide an added advantage, as it not only has economical production of PHA but due to $\mathrm{CO}_{2}$ sequestering capabilities can help in reducing global warming effect and can reduce pollution by providing alternative of synthetic plastic.

\section{AUTHOR CONTRIBUTIONS}

RA, ST, and MS have contributed toward conceptualization and framing the review content for PHA production from microbes. GS has contributed for the conceptualization and integration of mathematical/metabolic model aspect. All authors contributed to the article and approved the submitted version.

\section{FUNDING}

This work was supported by SERB projects ECR/2017/001130 and ECR/2017/003480.

\section{ACKNOWLEDGMENTS}

We are thankful to the Principal, Gargi College, New Delhi, for providing the necessary facilities and moral support.

a sustainable approach. J. Appl. Phycol. 28, 161-168. doi: 10.1007/s10811-0150573-x

Bhatia, S. K., Otari, S. V., Jeon, J.-M., Gaurav, R., Choi, Y.-K., Bhatia, R. V., et al. (2021). Biowaste-to-bioplastic (Polyhydroxyalkanoates): conversion technologies, strategies, challenges and perspectives. Bioresour. Technol. 326:124733. doi: 10.1016/j.biortech.2021.124733

Borowitzka, M. A. (2013). High-value products from microalgae-their development and commercialisation. J. Appl. Phycol. 25, 743-756. doi: 10.1007/s10811-013-9983-9

Brojanigo, S., Parro, E., Cazzorla, T., Favaro, L., Basaglia, M., and Casella, S. (2020). Conversion of starchy waste streams into polyhydroxyalkanoates using Cupriavidus necator DSM 545. Polymers 12:1496. doi: 10.3390/polym 12071496

Carpine, R., Du, W., Olivieri, G., Pollio, A., Hellingwerf, K. J., Marzocchella, A., et al. (2017). Genetic engineering of Synechocystis sp. PCC6803 for poly- $\beta$ hydroxybutyrate overproduction. Algal Res. 25, 117-127. doi: 10.1016/j.algal. 2017.05.013

Carpine, R., Olivieri, G., Hellingwerf, K., Pollio, A., and Marzocchella, A. (2015). The cyanobacterial route to produce poly- $\beta$-hydroxybutyrate. Chem. Eng. Trans. 43, 289-294.

da Silva, L. G., Gamez, K. O., Gomes, J. C., Akkermans, K., Welles, L., Abbas, B., et al. (2020). Revealing the metabolic flexibility of Candidatus Accumulibacter phosphatis through redox cofactor analysis and metabolic network modeling. Appl. Environ. Microbiol. 86:e00808-20.

De Philippis, R., Sili, C., and Vincenzini, M. (1992). Glycogen and poly- $\beta$ hydroxybutyrate synthesis in Spirulina maxima. Microbiology 138, 1623-1628. doi: 10.1099/00221287-138-8-1623

Deschoenmaeker, F., Facchini, R., Carlos, J., Pino, C., Bayon-Vicente, G., Sachdeva, N., et al. (2016). Nitrogen depletion in Arthrospira sp. PCC 8005, an ultrastructural point of view. J. Struct. Biol. 196, 385-393. doi: 10.1016/j.jsb. 2016.08.007

Dias, J. M., Oehmen, A., Serafim, L. S., Lemos, P. C., Reis, M. A., and Oliveira, R. (2008). Metabolic modelling of polyhydroxyalkanoate copolymers production 
by mixed microbial cultures. BMC Syst. Biol. 2:59. doi: 10.1186/1752-05 09-2-59

Drosg, B., Fritz, I., Gattermayr, F., and Silvestrini, L. (2015). Photo-autotrophic production of poly (hydroxyalkanoates) in cyanobacteria. Chem. Biochem. Eng. Q. 29, 145-156. doi: 10.15255/cabeq.2014.2254

Fradinho, J. C., Domingos, J. M. B., Carvalho, G., Oehmen, A., and Reis, M. A. M. (2013a). Polyhydroxyalkanoates production by a mixed photosynthetic consortium of bacteria and algae. Bioresour. Technol. 132, 146-153. doi: 10. 1016/j.biortech.2013.01.050

Fradinho, J. C., Oehmen, A., and Reis, M. A. M. (2013b). Effect of dark/light periods on the polyhydroxyalkanoate production of a photosynthetic mixed culture. Bioresour. Technol. 148, 474-479. doi: 10.1016/j.biortech.2013.09.010

Gill, M. (2014). Bioplastic: a better alternative to plastics. Int. J. Res. Appl. Nat. Soc. Sci. 2, 115-120.

Goo, B. G., Baek, G., Choi, D. J., Park, Y. I., Synytsya, A., Bleha, R., et al. (2013). Characterization of a renewable extracellular polysaccharide from defatted microalgae Dunaliella tertolecta. Bioresour. Technol. 129, 343-350. doi: 10.1016/ j.biortech.2012.11.077

Gopi, K., Balaji, S., and Muthuvelan, B. (2014). Isolation purification and screening of biodegradable polymer $\mathrm{PHB}$ producing cyanobacteria from marine and fresh water resources. Iran. J. Energy Environ. 5, 94-100. doi: 10.5829/idosi.ijee.2014. 05.01.14

Guerra-Renteria, A. S., García-Ramírez, M. A., Gómez-Hermosillo, C., GómezGuzmán, A., González-García, Y., and González-Reynoso, O. (2019). Metabolic pathway analysis of nitrogen and phosphorus uptake by the consortium between C. vulgaris and P. aeruginosa. Int. J. Mol. 20:1978. doi: 10.3390/ ijms 20081978

Gupta, S., Singh, G. P., and Kumawat, S. (2019). Petri net recommender system to model metabolic pathway of polyhydroxyalkanoates. Int. J. Knowl. Syst. Sci. 10, 42-59. doi: 10.4018/ijkss.2019040103

Haase, S. M., Huchzermeyer, B., and Rath, T. (2012). PHB accumulation in Nostoc muscorum under different carbon stress situations. J. Appl. Phycol. 24, 157-162. doi: 10.1007/s10811-011-9663-6

Hai, T., Hein, S., and Steinbüchel, A. (2001). Multiple evidence for widespread and general occurrence of type-III PHA synthases in cyanobacteria and molecular characterization of the PHA synthases from two thermophilic cyanobacteria: Chlorogloeopsis fritschii PCC 6912 and Synechococcus sp. strain MA19. Microbiology 147, 3047-3060. doi: 10.1099/00221287-147-11-3047

Hanly, T. J., and Henson, M. A. (2011). Dynamic flux balance modeling of microbial co-cultures for efficient batch fermentation of glucose and xylose mixtures. Biotechnol. Bioeng. 108, 376-385. doi: 10.1002/bit.22954

Hanly, T. J., and Henson, M. A. (2013). Dynamic metabolic modeling of a microaerobic yeast co-culture: predicting and optimizing ethanol production from glucose/xylose mixtures. Biotechnol. Biofuel. 6:44. doi: 10.1186/17546834-6-44

Hendry, J. I., Bandyopadhyay, A., Srinivasan, S., Pakrasi, H. B., and Maranas, C. D. (2020). Metabolic model guided strain design of cyanobacteria. Curr. Opin. Biotechnol. 64, 17-23. doi: 10.1016/j.copbio.2019.08.011

Hondo, S., Takahashi, M., Osanai, T., Matsuda, M., Hasunuma, T., Tazuke, A., et al. (2015). Genetic engineering and metabolite profiling for overproduction of polyhydroxybutyrate in cyanobacteria. J. Biosci. Bioeng. 120, 510-517. doi: 10.1016/j.jbiosc.2015.03.004

Jiang, Y., Hebly, M., Kleerebezem, R., Muyzer, G., and van Loosdrecht, M. C. (2011). Metabolic modeling of mixed substrate uptake for polyhydroxyalkanoate (PHA) production. Water Res. 45, 1309-1321. doi: 10.1016/j.watres.2010.10.009

Kaewbai-ngam, A., Incharoensakdi, A., and Monshupanee, T. (2016). Increased accumulation of polyhydroxybutyrate in divergent cyanobacteria under nutrient-deprived photoautotrophy: an efficient conversion of solar energy and carbon dioxide to polyhydroxybutyrate by Calothrix scytonemicola TISTR 8095. Bioresour. Technol. 212, 342-347. doi: 10.1016/j.biortech.2016.04.035

Kalia, V. C., Patel, S. K. S., Shanmugam, R., and Lee, J.-K. (2021). Polyhydroxyalkanoates: trends and advances toward biotechnological applications. Bioresour. Technol. 326:124737. doi: 10.1016/j.biortech.2021. 124737

Kamravamanesh, D., Kovacs, T., Pflügl, S., Druzhinina, I., Kroll, P., Lackner, M., et al. (2018a). Increased poly- $\beta$-hydroxybutyrate production from carbon dioxide in randomly mutated cells of cyanobacterial strain Synechocystis sp.
PCC 6714: mutant generation and characterization. Bioresour. Technol. 266, 34-44. doi: 10.1016/j.biortech.2018.06.057

Kamravamanesh, D., Lackner, M., and Herwig, C. (2018b). Bioprocess engineering aspects of sustainable polyhydroxyalkanoate production in cyanobacteria. Bioengineering 5:111. doi: 10.3390/bioengineering5040111

Kamravamanesh, D., Pflügl, S., Nischkauer, W., Limbeck, A., Lackner, M., and Herwig, C. (2017). Photosynthetic poly- $\beta$-hydroxybutyrate accumulation in unicellular cyanobacterium Synechocystis sp, PCC 6714. AMB Express 7:143.

Kansal, S., Singh, G. P., and Acharya, M. (2015). On the problem of characterizing Boolean Petri nets. Int. J. Comput. Appl. 975, 1-4. doi: 10.5120/ijca2015906441

Khetkorn, W., Incharoensakdi, A., Lindblad, P., and Jantaro, S. (2016). Enhancement of poly-3-hydroxybutyrate production in Synechocystis sp. PCC 6803 by overexpression of its native biosynthetic genes. Bioresour. Technol. 214, 761-768. doi: 10.1016/j.biortech.2016.05.014

Koch, I. (2015). Petri nets in systems biology. Soft. Sys. Model. 14, 703-710.

Koch, I., Nöthen, J., and Schleiff, E. (2017). Modeling the metabolism of Arabidopsis thaliana: application of network decomposition and network reduction in the context of Petri nets. Front. Genet. 8:85. doi: 10.3389/fgene.2017.00085

Kovalcik, A., Meixner, K., Mihalic, M., Zeilinger, W., Fritz, I., Fuchs, W., et al. (2017). Characterization of polyhydroxyalkanoates produced by Synechocystis salina from digestate supernatant. Int. J. Biol. Macromol. 102, 497-504. doi: 10.1016/j.ijbiomac.2017.04.054

Kumar, P., and Kim, B. S. (2018). Valorization of polyhydroxyalkanoates production process by co-synthesis of value-added products. Bioresour. Technol. 269, 544-556. doi: 10.1016/j.biortech.2018.08.120

Kumar, P., Maharjan, A., Jun, H. B., and Kim, B. S. (2019). Bioconversion of lignin and its derivatives into polyhydroxyalkanoates: challenges and opportunities. Biotechnol. Appl. Biochem. 66, 153-162. doi: 10.1002/bab.1720

Kumar, P., Patel, S. K., Lee, J. K., and Kalia, V. C. (2013). Extending the limits of Bacillus for novel biotechnological applications. Biotechnol. Adv. 31, 15431561. doi: 10.1016/j.biotechadv.2013.08.007

Kumar, P., Singh, M., Mehariya, S., Patel, S. K., Lee, J. K., and Kalia, V. C. (2014). Ecobiotechnological approach for exploiting the abilities of Bacillus to produce co-polymer of polyhydroxyalkanoate. Indian J. Microbiol. 54, 151-157. doi: 10.1007/s12088-014-0457-9

Lama, L., Nicolaus, B., Calandrelli, V., Manca, M. C., Romano, I., and Gambacorta, A. (1996). Effect of growth conditions on endo-and exopolymer biosynthesis in Anabaena cylindrica 10 C. Phytochemistry 42, 655-659. doi: 10.1016/00319422(95)00985- $\mathrm{x}$

Lau, N. S., Foong, C. P., Kurihara, Y., Sudesh, K., and Matsui, M. (2014). RNA-Seq analysis provides insights for understanding photoautotrophic polyhydroxyalkanoate production in recombinant Synechocystis Sp. PLoS One 9:e86368. doi: 10.1371/journal.pone.0086368

Lee, N. R., Lee, C. H., Lee, D. Y., and Park, J. B. (2020). Genomescale metabolic network reconstruction and in silico analysis of hexanoic acid producing Megasphaera elsdenii. Microorganisms 8:539. doi: 10.3390/ microorganisms 8040539

Lowe, H., Hobmeier, K., Moos, M., Kremling, A., and Pflüger-Grau, K. (2017). Photoautotrophic production of polyhydroxyalkanoates in a synthetic mixed culture of Synechococcus elongatus cscB and Pseudomonas putida cscAB. Biotechnol. Biofuels 10:190. doi: 10.1186/s13068-017-0875-0

Lu, Y. M., Xiang, W. Z., and Wen, Y. H. (2011). Spirulina (Arthrospira) industry in Inner Mongolia of China: current status and prospects. J. Appl. Phycol. 23, 265-269. doi: 10.1007/s10811-010-9552-4

Mallick, N., Gupta, S., Panda, B., and Sen, R. (2007). Process optimization for poly (3-hydroxybutyrate-co-3-hydroxyvalerate) co-polymer production by Nostoc muscorum. Biochem. Eng. J. 37, 125-130. doi: 10.1016/j.bej.2007.04.002

Martins, R. G., Gonçalves, I. S., Morais, M. G. D., and Costa, J. A. V. (2017). New technologies from the bioworld: selection of biopolymer-producing microalgae. Polimeros 27, 285-289. doi: 10.1590/0104-1428.2375

Mendes, A., Reis, A., Vasconcelos, R., Guerra, P., and da Silva, T. L. (2009). Crypthecodinium cohnii with emphasis on DHA production: a review. J. Appl. Phycol. 21, 199-214. doi: 10.1007/s10811-008-9351-3

Miyake, M., Erata, M., and Asada, Y. (1996). A thermophilic cyanobacterium, Synechococcus sp. MA19, capable of accumulating poly- $\beta$-hydroxybutyrate. J. Ferment Bioeng. 82, 512-514. doi: 10.1016/s0922-338x(97)86995-4

Mulbry, W., Kondrad, S., Pizarro, C., and Kebede-Westhead, E. (2008). Treatment of dairy manure effluent using freshwater algae: algal productivity and recovery 
of manure nutrients using pilot-scale algal turf scrubbers. Bioresour. Technol. 99, 8137-8142. doi: 10.1016/j.biortech.2008.03.073

Nahar, S., Jeong, M. H., and Hur, J. S. (2019). Lichen-associated bacterium, a novel bioresource of polyhydroxyalkanoate (PHA) production and simultaneous degradation of naphthalene and anthracene. J. Microbiol. Biotechnol. 29, 79-90. doi: 10.4014/jmb.1808.08037

Nishioka, M., Nakai, K., Miyake, M., Asada, Y., and Taya, M. (2001). Production of poly- $\beta$-hydroxybutyrate by thermophilic cyanobacterium, Synechococcus sp. MA19, under phosphate-limited conditions. Biotechnol. Lett. 23, 1095-1099.

Novak, M., Koller, M., Braunegg, M., and Horvat, P. (2015). Mathematical modelling as a tool for optimized PHA production. Chem. Biochem. Eng. Q. 29, 183-220. doi: 10.15255/cabeq.2014.2101

Olaizola, M., and Huntley, M. E. (2003). "Recent advances in commercial production of astaxanthin from microalgae," in Recent Advances in Marine Biotechnology. Biomaterials and Bioprocessing, Vol. 9, eds M. Fingerman, R. Nagabhushaman (Enfield, NH: Science Publishers), 143-164.

Olguín, E. J., Galicia, S., Mercado, G., and Pérez, T. (2003). Annual productivity of Spirulina (Arthrospira) and nutrient removal in a pig wastewater recycling process under tropical conditions. J. Appl. Phycol. 15, 249-257. doi: 10.1023/a: 1023856702544

Osanai, T., Numata, K., Oikawa, A., Kuwahara, A., Iijima, H., Doi, Y., et al. (2013). Increased bioplastic production with an RNA polymerase sigma factor SigE during nitrogen starvation in Synechocystis sp. PCC 6803. DNA Res. 20, 525-535. doi: 10.1093/dnares/dst028

Panda, B., Jain, P., Sharma, L., and Mallick, N. (2006). Optimization of cultural and nutritional conditions for accumulation of poly- $\beta$-hydroxybutyrate in Synechocystis sp. PCC 6803. Bioresour. Technol. 97, 1296-1301. doi: 10.1016/ j.biortech.2005.05.013

Panda, B., and Mallick, N. (2007). Enhanced poly- $\beta$-hydroxybutyrate accumulation in a unicellular cyanobacterium, Synechocystis sp. PCC 6803. Lett. Appl. Microbiol. 44, 194-198. doi: 10.1111/j.1472-765x.2006.02048.x

Panda, B., Sharma, L., and Mallick, N. (2005). Poly- $\beta$-hydroxybutyrate accumulation in Nostoc muscorum and Spirulina platensis under phosphate limitation. J. Plant Physiol. 162, 1376-1379. doi: 10.1016/j.jplph.2005.05.002

Pillai, A. B., Kumar, A. J., and Kumarapillai, H. (2019). "Synthetic biology and metabolic engineering approaches for improved production and recovery of bacterial polyhydroxyalkanoates," in Next Generation Biomanufacturing Technologies, eds N. K. Rathinam, and R. K. Sani (Washington, DC: American Chemical Society), 181-207. doi: 10.1021/bk-2019-1329.ch009

Rahman, A., Anthony, R. J., Sathish, A., Sims, R. C., and Miller, C. D. (2014). Effects of wastewater microalgae harvesting methods on polyhydroxybutyrate production. Bioresour. Technol. 156, 364-367. doi: 10.1016/j.biortech.2014.01. 034

Rahman, A., Linton, E., Hatch, A. D., Sims, R. C., and Miller, C. D. (2013). Secretion of polyhydroxybutyrate in Escherichia coli using a synthetic biological engineering approach. J. Biol. Eng. 7:24. doi: 10.1186/1754-1611-7-24

Ratledge, C. (2004). Fatty acid biosynthesis in microorganisms being used for single cell oil production. Biochimie 86, 807-815. doi: 10.1016/j.biochi.2004. 09.017

Ray, S., and Kalia, V. C. (2017). Co-metabolism of substrates by Bacillus thuringiensis regulates polyhydroxyalkanoate co-polymer composition. Bioresour. Technol. 224, 743-747. doi: 10.1016/j.biortech.2016.11.089

Roja, K., Sudhakar, D. R., Anto, S., and Mathimani, T. (2019). Extraction and characterization of polyhydroxyalkanoates from marine green alga and cyanobacteria. Biocatal. Agric. Biotechnol. 22:101358. doi: 10.1016/j.bcab.2019. 101358

Samantaray, S., and Mallick, N. (2012). Production and characterization of poly- $\beta$ hydroxybutyrate (PHB) polymer from Aulosira fertilissima. J. Appl. Phycol. 24, 803-814. doi: 10.1007/s10811-011-9699-7

Samantaray, S., and Mallick, N. (2014). Production of poly (3-hydroxybutyrate-co3-hydroxyvalerate) co-polymer by the diazotrophic cyanobacterium Aulosira fertilissima CCC 444. J. Appl. Phycol. 26, 237-245. doi: 10.1007/s10811-0130073-9

Samantaray, S., Nayak, J. K., and Mallick, N. (2011). Wastewater utilization for poly- $\beta$-hydroxybutyrate production by the cyanobacterium Aulosira fertilissima in a recirculatory aquaculture system. Appl. Environ. Microbiol. 77, 8735-8743. doi: 10.1128/aem.05275-11
Sankhla, I. S., Bhati, R., Singh, A. K., and Mallick, N. (2010). Poly (3hydroxybutyrate-co-3-hydroxyvalerate) co-polymer production from a local isolate, Brevibacillus invocatus MTCC 9039. Bioresour. Technol. 101, 1947-1953. doi: 10.1016/j.biortech.2009.10.006

Schlebusch, M., and Forchhammer, K. (2010). The nitrogen starvation induced protein Sllo783 is required for PHB accumulation in Synechocystis sp. strain PCC 6803. Appl. Environ. Microbiol. 101, 1947-1953.

Sharma, L., and Mallick, N. (2005a). Accumulation of poly- $\beta$-hydroxybutyrate in Nostoc muscorum: regulation by $\mathrm{pH}$, light-dark cycles, $\mathrm{N}$ and $\mathrm{P}$ status and carbon sources. Bioresour. Technol. 96, 1304-1310. doi: 10.1016/j.biortech. 2004.10.009

Sharma, L., and Mallick, N. (2005b). Enhancement of poly- $\beta$-hydroxybutyrate accumulation in Nostoc muscorum under mixotrophy, chemoheterotrophy and limitations of gas-exchange. Biotechnol. Lett. 27, 59-62. doi: 10.1007/s10529004-6586- 1

Sharma, L., Singh, A. K., Panda, B., and Mallick, N. (2007). Process optimization for poly- $\beta$-hydroxybutyrate production in a nitrogen fixing cyanobacterium, Nostoc muscorum using response surface methodology. Bioresour. Technol. 98, 987-993. doi: 10.1016/j.biortech.2006.04.016

Sharma, V., Sehgal, R., and Gupta, R. (2020). Polyhydroxyalkanoate (PHA): properties and modifications. Polymer 212:123161. doi: 10.1016/j.polymer. 2020.123161

Shen, F., Sun, R., Yao, J., Li, J., Liu, Q., Price, N. D., et al. (2019). OptRAM: insilico strain design via integrative regulatory-metabolic network modeling. PLoS Comput. Biol. 15:e1006835. doi: 10.1371/journal.pcbi.1006835

Shen, M., Song, B., Zeng, G., Zhang, Y., Huang, W., Wen, X., et al. (2020). Are biodegradable plastics a promising solution to solve the global plastic pollution? Environ. Pollut. 263:114469. doi: 10.1016/j.envpol.2020.114469

Shrivastav, A., Mishra, S. K., and Mishra, S. (2010). Polyhydroxyalkanoate (PHA) synthesis by Spirulina subsalsa from Gujarat coast of India. Int. J. Biol. Macromol. 46, 255-260. doi: 10.1016/j.ijbiomac.2010.01.001

Singh, A. K., and Mallick, N. (2017). Advances in cyanobacterial polyhydroxyalkanoates production. FEMS Microbiol. Lett. 364:fnx189.

Singh, G. P., and Jha, M. (2019). Petri net modeling and property analysis of C3 plant photosynthesis and photorespiration. [Preprint]. doi: 10.21203/rs.2. $15608 / \mathrm{vl}$

Singh, G. P., Jha, M., and Singh, M. (2020). Modeling the mechanism pathways of first line drug in Tuberculosis using Petri nets. Int. J. Sys. Assur. Eng. Manag 11, 313-324. doi: 10.1007/s13198-019-00940-4

Singh, M., Kumar, P., Ray, S., and Kalia, V. C. (2015). Challenges and opportunities for customizing polyhydroxyalkanoates. Indian J. Microbiol. 55, 235-249. doi: 10.1007/s12088-015-0528-6

Singh, M., Patel, S. K., and Kalia, V. C. (2009). Bacillus subtilis as potential producer for polyhydroxyalkanoates. Microb. Cell Fact. 8:38. doi: 10.1186/1475-2859-838

Singh, M. K., Rai, P. K., Rai, A., Singh, S., and Singh, J. S. (2019). Poly$\beta$-hydroxybutyrate production by the cyanobacterium Scytonema geitleri Bharadwaja under varying environmental conditions. Biomolecules 9:198. doi: 10.3390/biom9050198

Singh, S., Kate, B. N., and Banerjee, U. C. (2005). Bioactive compounds from cyanobacteria and microalgae: an overview. Crit. Rev. Biotechnol. 25, 73-95. doi: $10.1080 / 07388550500248498$

Spolaore, P., Joannis-Cassan, C., Duran, E., and Isambert, A. (2006). Commercial applications of microalgae. J. Biosci. Bioeng. 101, 87-96. doi: 10.1263/jbb.101.87

Stal, L. J., Heyer, H., and Jacobs, G. (1990). "Occurrence and role of poly-hydroxyalkanoate in the cyanobacterium Oscillatoria limosa," in Novel Biodegradable Microbial Polymers, ed. E.A. Dawes (Dordrecht: Springer), 435-438. doi: 10. 1007/978-94-009-2129-0 38

Stolyar, S., Van Dien, S., Hillesland, K. L., Pinel, N., Lie, T. J., Leigh, J. A., et al. (2007). Metabolic modeling of a mutualistic microbial community. Mol. Syst. Biol. 3:92. doi: $10.1038 / \mathrm{msb} 4100131$

Sudesh, K., Taguchi, K., and Doi, Y. (2001). Can Cyanobacteria be a Potential PHA Producer? Available online at: http://citeseerx.ist.psu.edu/viewdoc/download? doi=10.1.1.224.5203\&rep=rep1\&type $=$ pdf (accessed July 13, 2021).

Sudesh, K., Taguchi, K., and Doi, Y. (2002). Effect of increased PHA synthase activity on polyhydroxyalkanoates biosynthesis in Synechocystis sp. PCC6803. Int. J. Biol. Macromol. 30, 97-104. doi: 10.1016/s0141-8130(02)00 010-7 
Taffs, R., Aston, J. E., Brileya, K., Jay, Z., Klatt, C. G., McGlynn, S., et al. (2009). In silico approaches to study mass and energy flows in microbial consortia: a syntrophic case study. BMC Syst. Biol. 3:114. doi: 10.1186/1752-050 9-3-114

Takahashi, H., Miyake, M., Tokiwa, Y., and Asada, Y. (1998). Improved accumulation of poly-3-hydroxybutyrate by a recombinant cyanobacterium. Biotechnol. Lett. 20, 183-186.

Troschl, C., Meixner, K., and Drosg, B. (2017). Cyanobacterial PHA productionReview of recent advances and a summary of three years' working experience running a pilot plant. Bioengineering 4:26. doi: 10.3390/bioengineering4020026

Troschl, C., Meixner, K., Fritz, I., Leitner, K., Romero, A. P., Kovalcik, A., et al. (2018). Pilot-scale production of poly- $\beta$-hydroxybutyrate with the cyanobacterium Synechocytis sp. CCALA192 in a non-sterile tubular photobioreactor. Algal Res. 34, 116-125. doi: 10.1016/j.algal.2018.07.011

Volkova, S., Matos, M. R., Mattanovich, M., and Marín de Mas, I. (2020). Metabolic modelling as a framework for metabolomics data integration and analysis. Metabolites 10:303. doi: 10.3390/metabo10080303

Wagner, J., Bransgrove, R., Beacham, T. A., Allen, M. J., Meixner, K., Drosg, B., et al. (2016). Co-production of bio-oil and propylene through the hydrothermal liquefaction of polyhydroxybutyrate producing cyanobacteria. Bioresour. Technol. 207, 166-174. doi: 10.1016/j.biortech.2016.01.114

Wang, B., Pugh, S., Nielsen, D. R., Zhang, W., and Meldrum, D. R. (2013). Engineering cyanobacteria for photosynthetic production of 3-hydroxybutyrate directly from CO2. Metab. Eng. 16, 68-77. doi: 10.1016/j.ymben.2013.01.001

Wang, B., Xiong, W., Yu, J., Maness, P. C., and Meldrum, D. R. (2018). Unlocking the photobiological conversion of CO 2 to (R)3-hydroxybutyrate in cyanobacteria. Green Chem. 20, 3772-3782. doi: 10.1039/C8GC01208C

Wilde, A., and Dienst, D. (2011). “Tools for genetic manipulation of cyanobacteria," in Bioenergetic Processes of Cyanobacteria, eds G. Peschek, C. Obinger, and G. Renger (Dordrecht: Springer), 685-703. doi: 10.1007/978-94-007-03889_24
Wu, D., Wang, Y., and Xu, X. (2020). Effects of a type I RM system on gene expression and glycogen catabolism in Synechocystis sp. PCC 6803. Front. Microbiol. 11:1258. doi: 10.3389/fmicb.2020.01258

Wu, G. F., Shen, Z. Y., and Wu, Q. Y. (2002). Modification of carbon partitioning to enhance PHB production in Synechocystis sp. PCC6803. Enzyme Microbial Technol. 30, 710-715. doi: 10.1016/S0141-0229(02)00044-3

$\mathrm{Wu}$, G. F., Wu, Q. Y., and Shen, Z. Y. (2001). Accumulation of poly- $\beta$ hydroxybutyrate in cyanobacterium Synechocystis sp. PCC6803. Bioresour. Technol. 76, 85-90. doi: 10.1016/S0960-8524(00)00099-7

Xu, P., Ranganathan, S., Fowler, Z. L., Maranas, C. D., and Koffas, M. A. (2011). Genome-scale metabolic network modeling results in minimal interventions that cooperatively force carbon flux towards malonyl-CoA. Metab. Eng. 13, 578-587. doi: 10.1016/j.ymben.2011.06.008

Zhang, S., Liu, Y., and Bryant, D. A. (2015). Metabolic engineering of Synechococcus sp. PCC 7002 to produce poly-3-hydroxybutyrate and poly-3-hydroxybutyrateco-4-hydroxybutyrate. Metab. Eng. 32, 174-183. doi: 10.1016/j.ymben.2015.10. 001

Zhang, S., Qian, X., Chang, S., Dismukes, G. C., and Bryant, D. A. (2016). Natural and synthetic variants of the tricarboxylic acid cycle in cyanobacteria: introduction of the GABA shunt into Synechococcus sp. PCC 7002. Front. Microbiol. 7:1972. doi: 10.3389/fmicb.2016.01972

Conflict of Interest: The authors declare that the research was conducted in the absence of any commercial or financial relationships that could be construed as a potential conflict of interest.

Copyright (C) 2021 Afreen, Tyagi, Singh and Singh. This is an open-access article distributed under the terms of the Creative Commons Attribution License (CC BY). The use, distribution or reproduction in other forums is permitted, provided the original author(s) and the copyright owner(s) are credited and that the original publication in this journal is cited, in accordance with accepted academic practice. No use, distribution or reproduction is permitted which does not comply with these terms. 